\title{
In vitro apoptotic and DNA damaging potential of nanobarium oxide
}

\author{
This article was published in the following Dove Press journal: \\ International Journal of Nanomedicine \\ 13 January 2016 \\ Number of times this article has been viewed
}

\author{
Saud Alarifi ${ }^{\prime}$ \\ Daoud Ali' \\ Widad Al-Bishri² \\ 'Department of Zoology, College \\ of Science, King Saud University, \\ Riyadh, Saudi Arabia; ${ }^{2}$ Department \\ of Biochemistry, Faculty of Science-Al \\ Faisaliah Campus, King Abdulaziz \\ University, Jeddah, Saudi Arabia
}

\begin{abstract}
Barium oxide nanoparticles (BaONPs) are an important industrial compound and are widely used in polymers and paints. In this study, apoptotic and genotoxic effects of BaONPs in mouse embryonic fibroblast (L929) cells were determined by using single-cell gel test. In vitro cytotoxicity assays were performed to assess BaONPs' toxicity in L929 cells. Mild cytotoxicity was observed in L929 cells due to BaONPs. BaONPs increased lipid peroxidation, catalase, and superoxide dismutase levels and lowered glutathione levels in L929 cells. This was accompanied by concomitant generation of reactive oxygen species and activation of caspase- 3 in BaONPs-treated L929 cells. On the other hand, when we exposed L929 cells to BaONPs for 24 and 48 hours (comet assay), there was a duration- and dose-dependent increase in DNA impairment detected in the single-cell gel test. Thus, BaONPs exhibit genotoxic and apoptotic effects in L929 cells, most likely due to initiation of oxidative damage.
\end{abstract}

Keywords: nanobarium oxide, L929 cells, DNA damage, apoptosis

\section{Introduction}

Engineered metal nanoparticles have been widely used in cosmetics, painting, textiles, and water treatments. Barium oxide nanoparticles (BaONPs) have been used in diagnostic imaging, orthopedic medicines, and other applications. ${ }^{1}$ Because of their increased use in human applications and their release into the environment, it has become important to study and understand the impact of nanoparticles on animal health. ${ }^{2}$ Hiraoka et $\mathrm{al}^{3}$ reported that barium induces automaticity in ventricular muscle. Nayler and Grinwald ${ }^{4}$ reported that marked contractures develop in the heart of rat, with depletion of tissue ATP and creatinine phosphate after perfusion with barium $(1.3 \mathrm{mM} / \mathrm{L})$ in place of calcium ions.

Even though there are existing studies on the toxicity of barium nanoparticles, the underlying machinery inducing toxicity remains unexplored till now. Moreover none of the studies, so far, have explored the adverse effect of BaONPs in mouse embryonic fibroblast cells. Ostrovsky et $\mathrm{al}^{5}$ reported that oxidative stress and reactive oxygen species (ROS) cause adverse effects such as apoptosis and DNA fragmentation. The toxic potential of BaONPs is of specific concern because the changes of the genetic materials have potential to cause cell death, cancer development, and reproductive adverse effects. ROS has been explained as a concerning factor in BaONPs toxicity. We have already found glutathione $(\mathrm{GSH})$ reduced as an oxidative biomarker and ROS as a group marker of $\mathrm{O}_{2}^{-}, \mathrm{OH}$ radicals, $\mathrm{H}_{2} \mathrm{O}_{2}$ and malondialdehyde (MDA) in reaction to $\mathrm{BaONPs}$ exposure.

So, this work was planned to measure the toxicity and genotoxic effect of BaONPs in L929 cells.
Department of Zoology, College of Science, King Saud University, Box 2455, Riyadh II45I, Saudi Arabia

Tel +96655890 462I

Fax +966 II $46785 \mid 4$

Email daudali.ksul2@yahoo.com
International Journal of Nanomedicine 2016: I | 249-257 


\section{Materials and methods}

\section{Ethics}

Ethics approval was not sought, as our University does not require it for in vitro studies.

\section{Chemicals}

BaONPs, 2, 7-dichlorofluorescin diacetate, DTNB, glutathione, and propidium iodide were acquired from Sigma-Aldrich, St Louis, MO, USA. Dulbecco's Modified Eagle's Medium (DMEM)/F-12 medium, were bought from Invitrogen Co. (Carlsbad, CA, USA).

\section{Characterization of BaONPs}

A suspension of BaONPs was prepared in DMEM $(1 \mathrm{mg} / \mathrm{mL})$ and sonicated in a sonicator with $40 \mathrm{~W}$ capacity for 15 minutes at room temperature to form a uniform suspension. The size of BaONPs was characterized by fieldemission transmission electron microscopy (FETEM). The hydrodynamic size of BaONPs were checked by dynamic light scattering (DLS; Nano-Zeta Sizer-HT, Malvern Instruments, Malvern, UK).

\section{L929 cells}

L929 cells were procured from ATCC (Rockville, MD, USA).

\section{Morphological analysis of cells}

The shape and size of L929 cells were observed by microscope (Leica DMIL, Leica Microsystems, Wetzlar, Germany) after exposure to BaONPs for 24 and 48 hours.

\section{MTT assay}

The cytotoxicity of L929 cells due to exposure to BaONPs $(0,50,100,150$, and $300 \mu \mathrm{g} / \mathrm{mL})$ for 24 and 48 hours was measured by MTT assay. ${ }^{6}$

\section{LDH assay}

Leakage of cytoplasmic lactate dehydrogenase (LDH) enzyme in L929 cells due to treatment with BaONPs $(0,50,100,150$, and $300 \mu \mathrm{g} / \mathrm{mL})$ for 24 and 48 hours was determined. $^{7}$

\section{Quantitation of ROS}

ROS production was evaluated in L929 cells after treatment with BaONPs $(0,50,100,150$, and $300 \mu \mathrm{g} / \mathrm{mL})$ by using DCFH-DA dye. ${ }^{8}$ To confirm the role of ROS, the cells were exposed to BaONPs $(300 \mu \mathrm{g} / \mathrm{mL})$ with and without $5 \mathrm{mM}$ $N$-acetylcysteine (NAC) for 24 hours.

\section{Estimation of oxidative parameters}

L929 cells, $\left(\sim 5 \times 10^{6}\right)$ seeded in a $75 \mathrm{~cm}^{2}$ flask, were treated with BaONPs $(0,50,100,150$, and $300 \mu \mathrm{g} / \mathrm{mL})$ for 24 and 48 hours. After treatment, the cells were scraped and washed with ice-cold phosphate-buffered saline (PBS). Scraped cells were broken down in lysing. These cells were centrifuged for 15 minutes at $12,000 \times g, 4^{\circ} \mathrm{C}$, and cell lysate was kept at $-20^{\circ} \mathrm{C}$ for testing oxidative stress parameters. The amount of protein in cell lysate was quantified by Bradford' ${ }^{9}$ method using bovine serum albumin as the standard.

Lipid peroxidation was evaluated by estimating the production of MDA by Ohkawa et al's ${ }^{10}$ method. Superoxide dismutase (SOD) and catalase (CAT) levels were measured by Alarifi et al's ${ }^{11}$ method. Glutathione level was estimated by using Ellman's reagent. ${ }^{12}$

\section{Chromosome condensation}

Condensation of chromosomes in L929 cells due to BaONPs exposure $(0,50,100,150$, and $300 \mu \mathrm{g} / \mathrm{mL})$ was observed using Hoechst 33342 dye. Treated and untreated cells were stained with Hoechst 33342 for 30 minutes at $37^{\circ} \mathrm{C}$ in dark. Photomicrographs of nuclei were taken by fluorescent microscope.

\section{Cysteine-aspartic acid protease- 3 activity}

Cells $\left(5 \times 10^{5}\right.$ cells/well) were spread on a culture plate (96 well) and incubated at $37^{\circ} \mathrm{C}$. Cells were exposed to different concentrations of BaONPs $(0,50,100,150$, and $300 \mu \mathrm{g} / \mathrm{mL})$ for 48 hours. Caspase-3 level was assessed by Alarifi and Ali's ${ }^{13}$ method. To confirm the role of ROS in caspase-3 activity, L929 cells were exposed to BaONPs $(150 \mu \mathrm{g} / \mathrm{mL})$ with and without $5 \mathrm{mM}$ NAC for 24 hours.

\section{Analysis of apoptosis through fluorescence-activated cell sorting}

Apoptosis was detected by using the Annexin V-FITC (fluorescein isothiocyanate) kit (Cayman Chemicals, Ann Arbor, MI, USA) according to manufacturer's information. After exposure to BaONPs ( $150 \mu \mathrm{g} / \mathrm{mL}$ ) for 24 and 48 hours, cells were trypsinized and washed with PBS and then incubated with binding buffer $(400 \mu \mathrm{L})$ containing propidium iodide $(20 \mu \mathrm{L})$ and Annexin V FITC $(10 \mu \mathrm{L})$ for 30 minutes in the dark at room temperature. The density of Annexin V-FITCpositive L929 cells was scrutinized by using fluorescenceactivated cell sorting (FACS) (BD Biosciences, San Jose, CA, USA). Cells in the initial phase of apoptosis were found in $\mathrm{Q}_{4}$ quadrant, while those in the delayed phase were found in $\mathrm{Q}_{1}$. The percentage of late apoptotic cells was plotted. 


\section{Comet assay}

Single-cell gel test was completed by Ali et al's $\mathrm{s}^{14}$ method.

\section{Analysis of data by statistics}

A minimum of three independent experiments in two replicates were done for each result. Results are presented as average ( \pm standard error) and investigated by analysis of variance. $P$-value less than 0.05 reflected statistical significance.

\section{Results}

\section{Changes in $\mathrm{L} 929$ cell lines}

Figure 1 unveils morphological changes in control cells and $\mathrm{L} 929$ cells treated with BaONPs for 48 hours. BaONPs $(300 \mu \mathrm{g} / \mathrm{mL}$ )-treated $\mathrm{L} 929$ cells changed into round shape and separated from the outer layers of the culture flask (Figure 1B and C).

\section{L929 cells toxicity}

BaONPs-induced cytotoxicity in L929 cells was observed as MTT declined, releasing lactate dehydrogenase enzymes. MTT results indicated a dose- and time-dependent cell toxicity in the wake of $\mathrm{L} 929$ cells were treated with BaONPs (Figure 2A). LDH discharge, a biomarker of cellular membrane damage, was estimated in L929 cells after exposure to BaONPs for 48 hours.

\section{Oxidative stress}

Induction of oxidative stress by BaONPs was evaluated by estimating the glutathione, lipid peroxidation, ROS, catalase, and superoxide dismutase levels in L929 cells. BaONPs incited ROS production in a dose- and duration-dependent manner (Figure 3). BaONPs-induced oxidative stress was further evidenced by depletion of glutathione and raise of lipid peroxide, superoxide dismutase, and catalase due to BaONPs exposure (Figure 4).

\section{Cysteine-aspartic acid protease-3 enzyme and apoptosis}

Caspase-3 enzyme shows main activity in apoptotic cells, which was caused due to BaONPs (Figure 5). After being exposed to BaONPs for 48 hours, the role of Cysteineaspartic acid protease- 3 increased in a dose- and durationdependent manner.

Staining of Annexin V-FITC and PI were applied to detect apoptotic and necrotic stimulation in L929 cells following BaONPs $(150 \mu \mathrm{g} / \mathrm{mL})$ exposure for 24 and 48 hours (Figure 6). Treatment with BaONPs indicated a significant
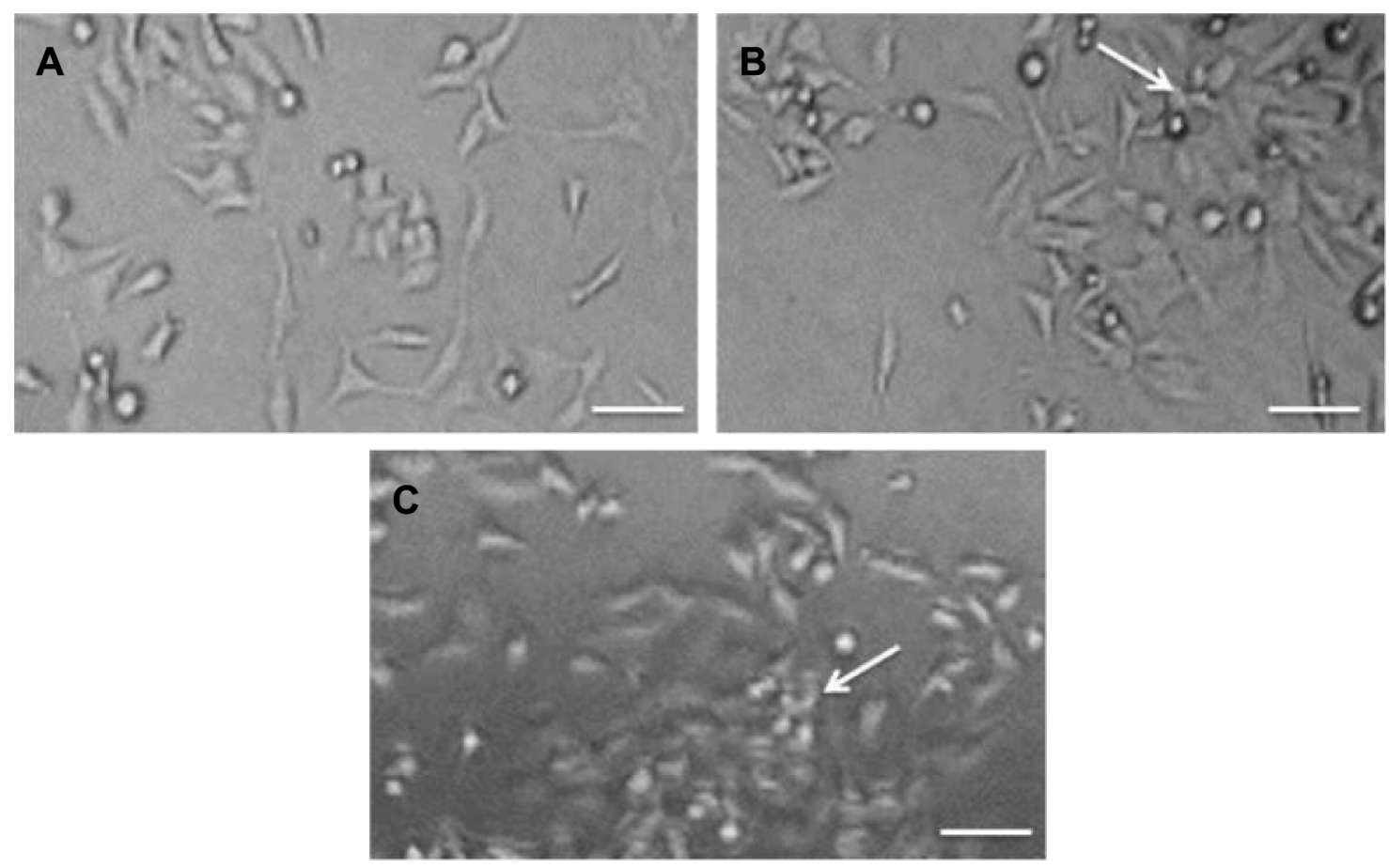

Figure I Shape and size of L929 cells.

Notes: (A) Untreated cells. (B) Cells with BaONPs (I50 $\mu \mathrm{g} / \mathrm{mL})$ for 24 hours. (C) Cells with BaONPs (I50 $\mu \mathrm{g} / \mathrm{mL})$ for 48 hours. Scale bar (- $) 50 \mu \mathrm{m}$. The arrows indicate damaged cells.

Abbreviation: BaONPs, barium oxide nanoparticles. 

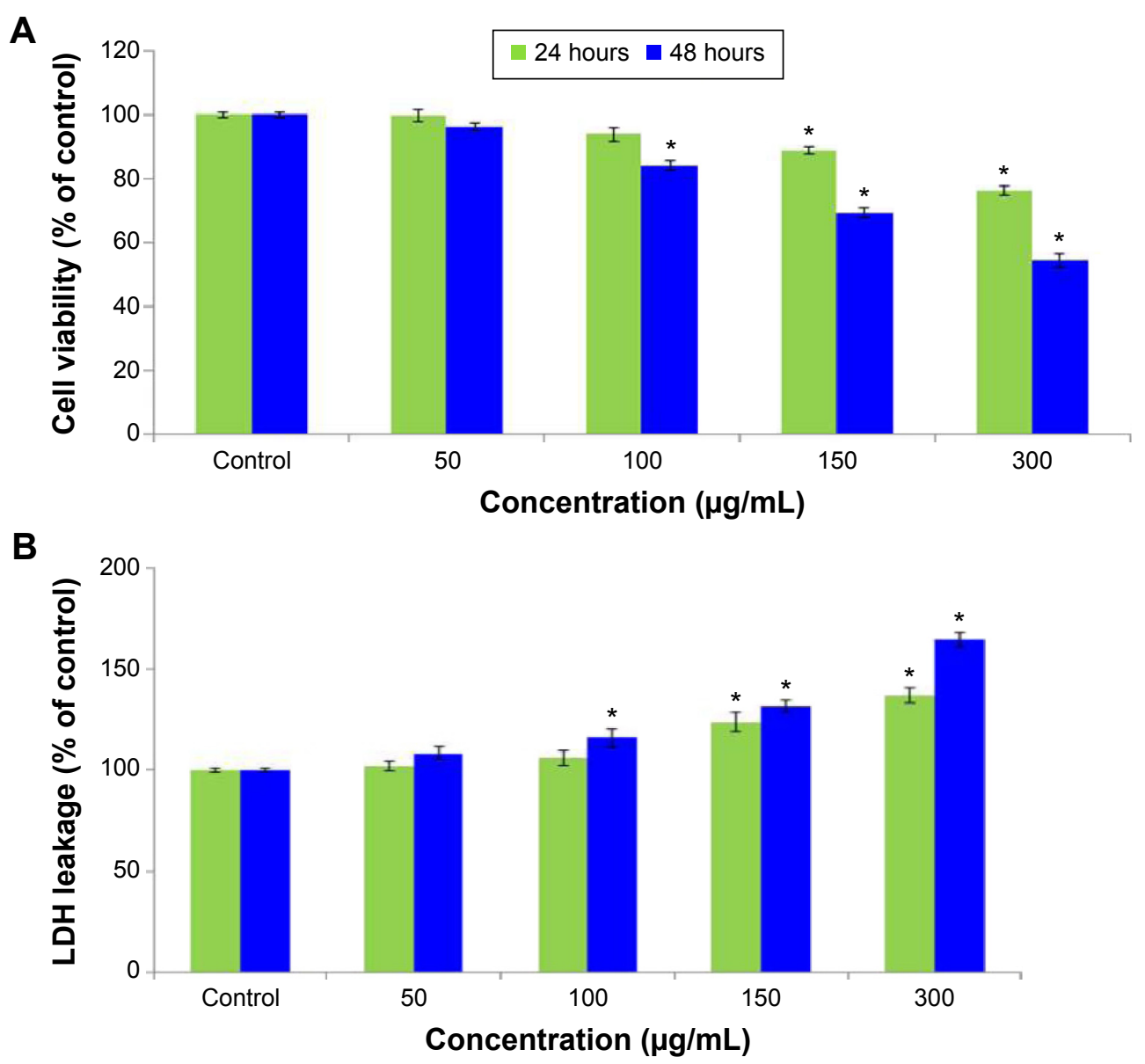

Figure 2 Cytotoxicity of BaONPs in mouse fibroblast cells over 48 hours, as assessed by (A) MTT and (B) LDH assays.

Notes: Data represent the average \pm SE of three tests. Statistical differences with respect to the controls are shown $(* P<0.05)$.

Abbreviations: BaONPs, barium oxide nanoparticles; LDH, lactate dehydrogenase; SE, standard error.

$(P<0.05)$ increase in late apoptotic cells in a durationdependent manner (Figure 6B-D).

\section{Impairment of DNA}

DNA impairment was assessed as \% tail DNA in untreated and BaONPs-treated L929 cells. L929 cells treated with $\mathrm{BaONPs}$ showed higher DNA damage than control. Notable damage of DNA was observed in BaONPs $(300 \mu \mathrm{g} / \mathrm{mL})$ treated L929 cells (Figure 7).

\section{Discussion}

This study suggested that BaONPs are slightly lethal to L929 cells, and this cell toxicity turns significant with dose and duration rise. Murdock et $a l^{15}$ reported that nanoparticles can induce adverse effects due to their small size and unique physiochemical characters. Nel et $\mathrm{al}^{16}$ reported that the key parameters of nanoparticles are structure, shape, purity, and hydrodynamical agglomeration, which control the biological activity of BaONPs.
Specific physical-chemical characters of BaONPs are due to surface area to volume ratio. Nanoparticles have a high percentage of atoms on their surface compared to macroparticles, studying the genotoxic effect of BaONPs, we had characterized their size and zeta potential of the BaONPs by FETEM and DLS, respectively. However, the hydrodynamic dimension obtained by DLS was greater than quantified size of FETEM.

L929 cells are commonly used to test the cytotoxic potential of nanoparticles. BaONPs induced caspase-3 activity and ROS in L929 cells. In this study, we observed that BaONPs increased cytotoxicity and apoptosis in L929 cells. Nel et al ${ }^{16}$ reported that the toxic effect of nanoparticles was due to oxidative stress. Oxidative stress provokes a long range of cellular and physiological events, eg, DNA damage, inflammation, apoptosis, and stress. ${ }^{17}$

Experimental evidence has shown that barium sulfate nanoparticles cause lung injury and inflammation in rats. ${ }^{18}$ During oxidative stress, the antioxidant mechanisms are 

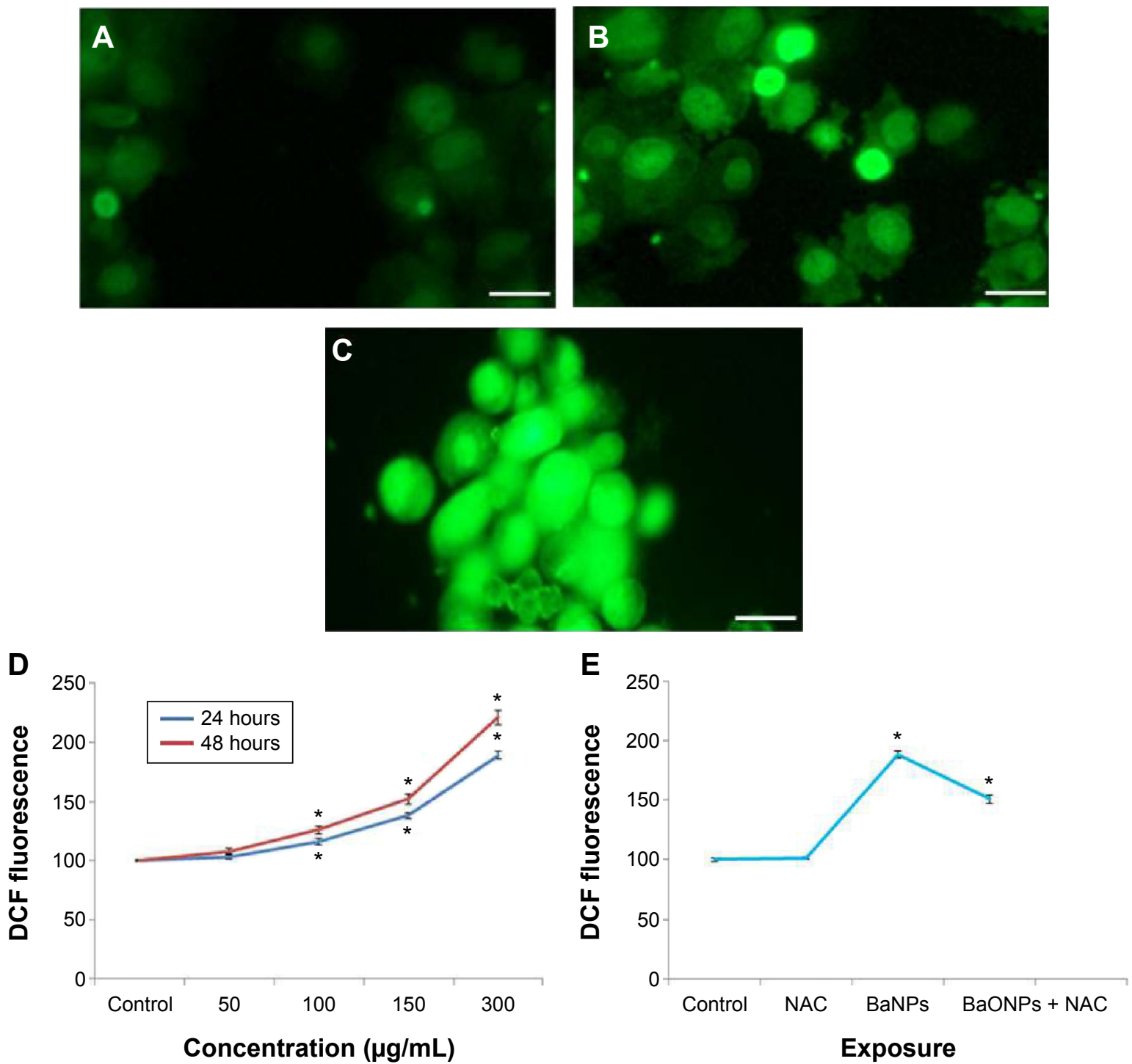

Figure 3 BaONPs produced ROS in L929 cells.

Notes: (A) Control; (B) L929 cells treated with $300 \mu \mathrm{g} / \mathrm{mL}$ of BaONPs for 24 hours; (C) L929 cells treated with $300 \mu \mathrm{g} / \mathrm{mL}$ of BaONPs for 48 hours. (D) \% ROS in L929 cells. (E) Effect of NAC (5 mM) on BaONPs $(300 \mu \mathrm{g} / \mathrm{mL})$-induced ROS generation in L929 cells. Data represent the average \pm SE of three tests. Statistical differences with respect to the controls are shown $(* P<0.05)$. Scale bar $(-)$ is $50 \mu \mathrm{m}$.

Abbreviations: BaONPs, barium oxide nanoparticles; DCF, dichlorofluorescein; ROS, reactive oxygen species; NAC, N-acetylcysteine; SE, standard error.

unable to counter ROS production. ROS, eg, $\mathrm{O}_{2}^{-}, \mathrm{H}_{2} \mathrm{O}_{2}$, and $\mathrm{OH}$ radicals, have a higher chemical activity than $\mathrm{O}_{2}$. Oberdorster et $\mathrm{al}^{19}$ reported that the reduction of GSH and stimulation of LPO and ROS induce oxidative damage of cell components. ROS, lipid peroxidation, and SOD activity was increased, whereas glutathione level was less in BaONPs-treated L929 cells. Glutathione was implicated in the first-line cellular defense mechanism against oxidative injury in cells. ${ }^{20}$

In this study, we found a correlation between the production of ROS and glutathione declination, suggesting that higher generation of ROS induces proliferated lipid peroxidation accompanying decline in GSH. Kang et $\mathrm{al}^{21}$ reported that oxidative stress and lipid peroxidation lead to apoptosis and DNA damage. During apoptosis, a chain of biochemical reactions occurs, inducing an alteration of L929 cell shape, and ultimately resulting in cell death.

Kroemer et $\mathrm{al}^{22}$ reported some biomarkers that characterize apoptosis, such as DNA fragmentation, cell membrane blebbing, condensation, shrinking, and disintegration of cell organelles. In this study, Hoechst 33342 staining of BaONPs-treated L929 cells gave rise to nuclear fragmentation and condensation. Chen et $\mathrm{al}^{23}$ demonstrated that nanomaterials interact with DNA due to their small size and shape. Nanoparticles can have an indirect effect on DNA production of ROS. ${ }^{24}$ The DNA damage can either induce 
A

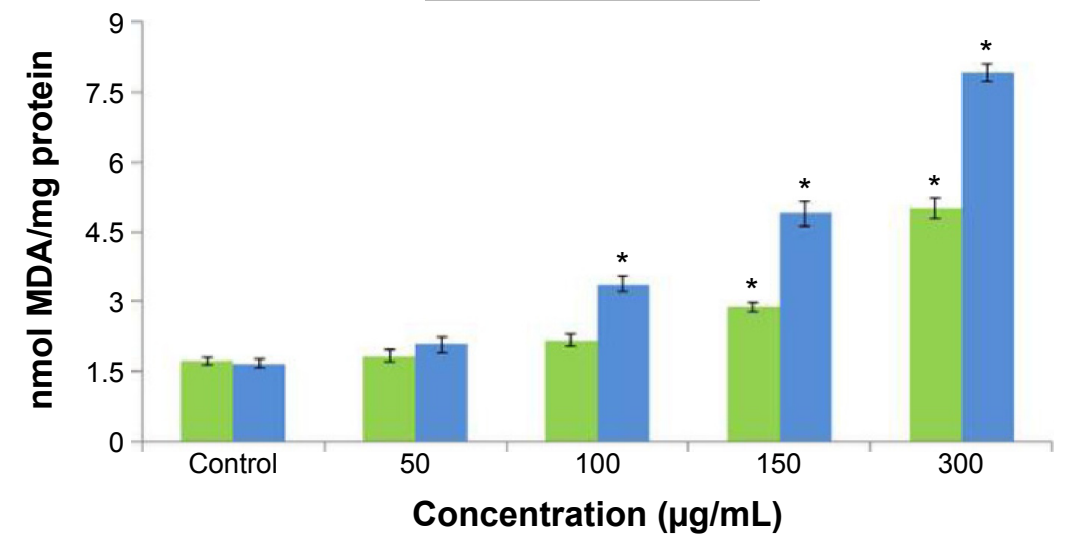

B

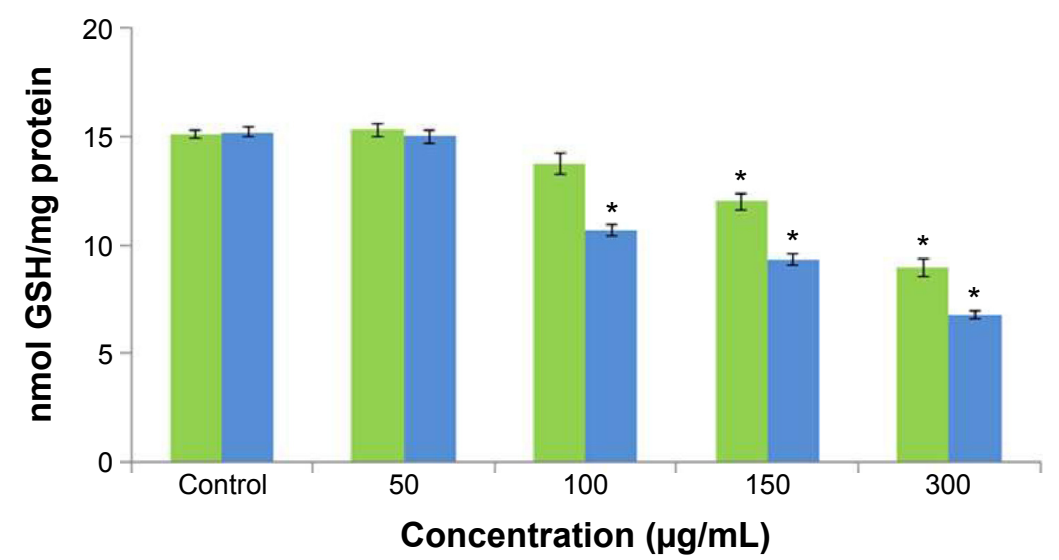

C
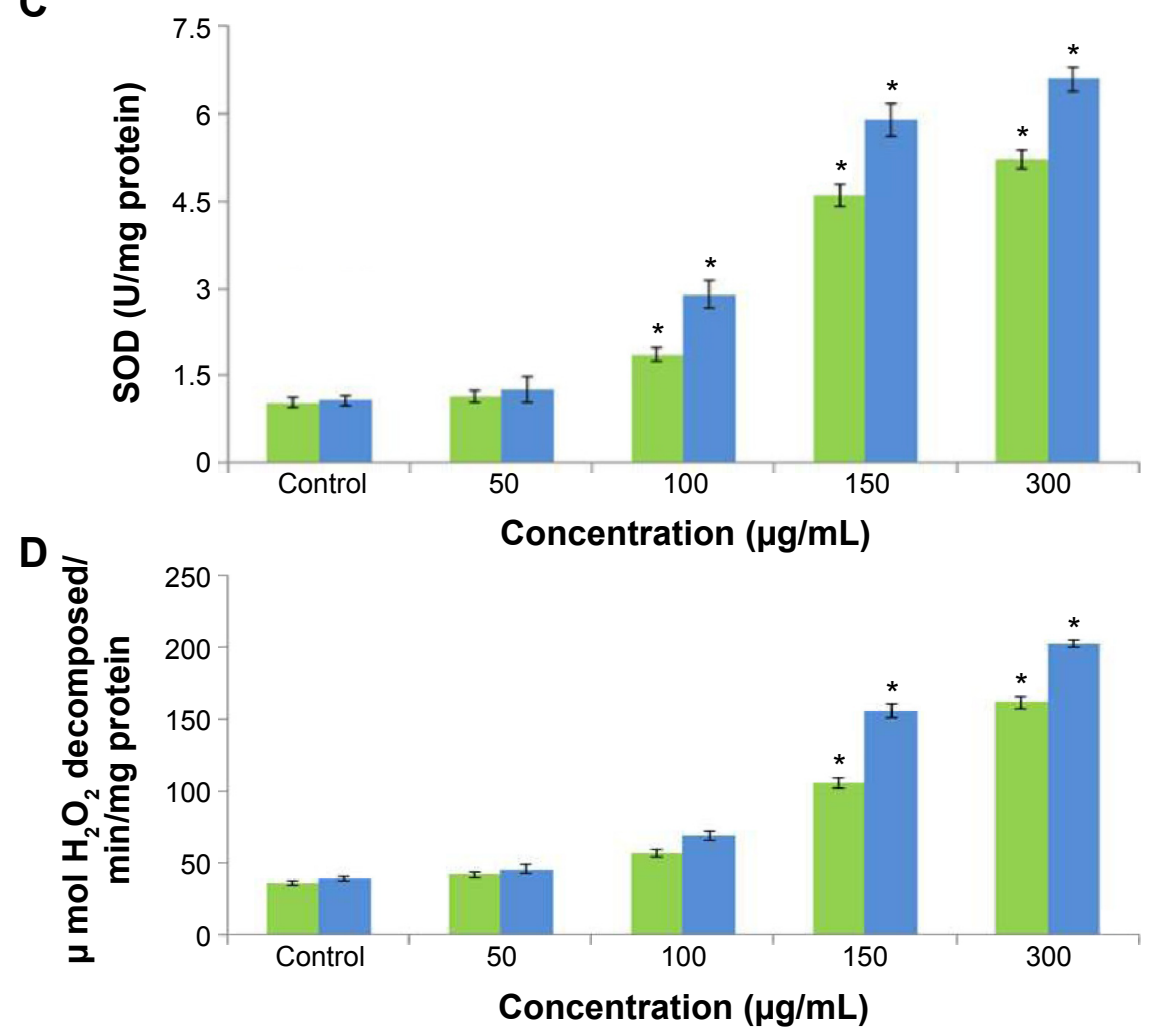

Figure 4 (A) Levels of lipid peroxidation; (B) glutathione; (C) SOD; and (D) catalase in L929 cells after exposure to BaONPs for 48 hours. Notes: Data represent the average \pm SE of three tests. Statistical differences with respect to the controls are shown $(* P<0.05)$.

Abbreviations: BaONPs, barium oxide nanoparticles; GSH, glutathione; SOD, superoxide dismutase; SE, standard error. 


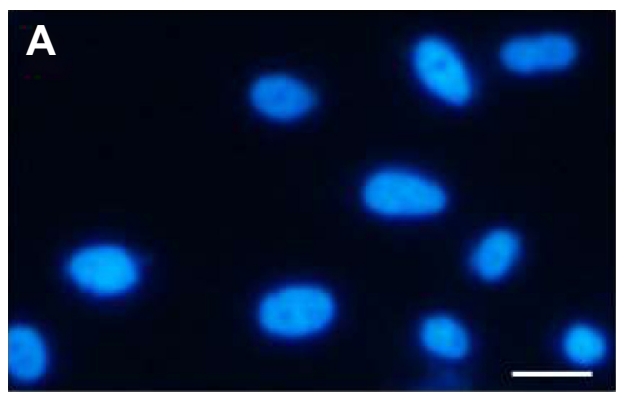

C

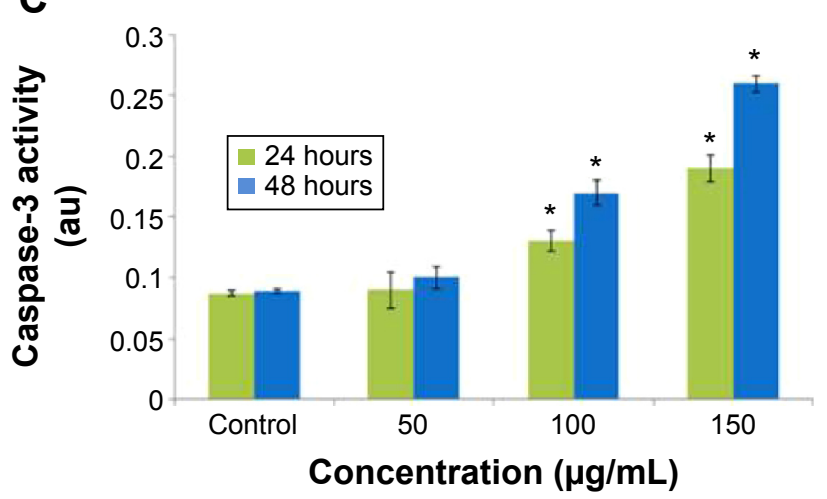

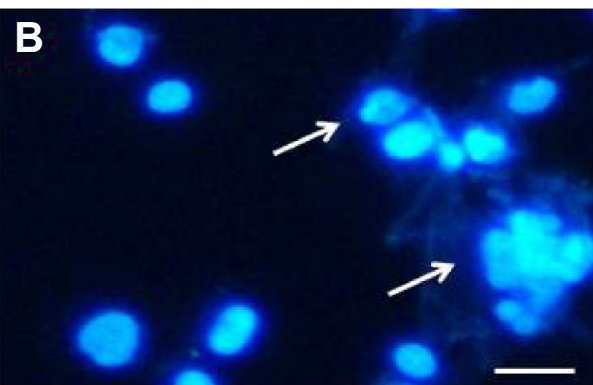

D

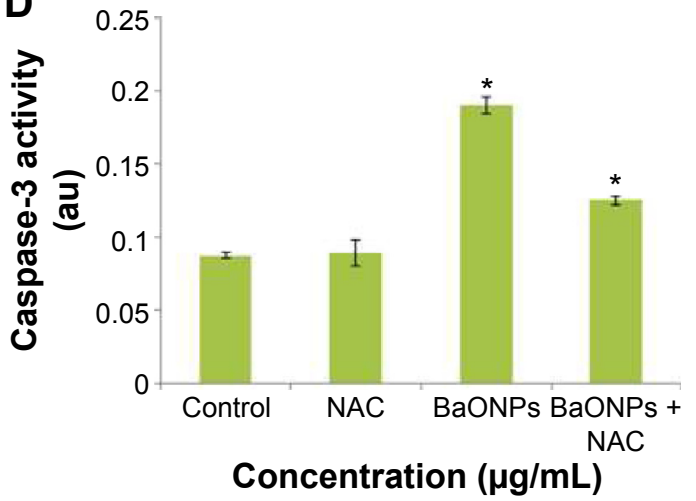

Figure 5 Chromatin condensation and stimulation of caspase-3 activity in L929 cells after exposure to BaONPs (A). Control (B) at I50 $\mu$ g/mL of BaONPs for 48 hours of BaONPs. (C) Caspase-3 activity. (D) Effect of NAC $(5 \mathrm{mM})$ on BaONPs $(150 \mu \mathrm{g} / \mathrm{mL})$ induced caspase-3 activity in L929 cells over 24 hours.

Notes: Data represent the average \pm SE of three tests. Statistical differences with respect to the controls are shown $(* P<0.05)$. Scale bar $(\longrightarrow) 50 \mu m$. The white arrows indicate the condensed chromosomes.

Abbreviations: BaONPs, barium oxide nanoparticles; NAC, N-acetylcysteine; SE, standard error.
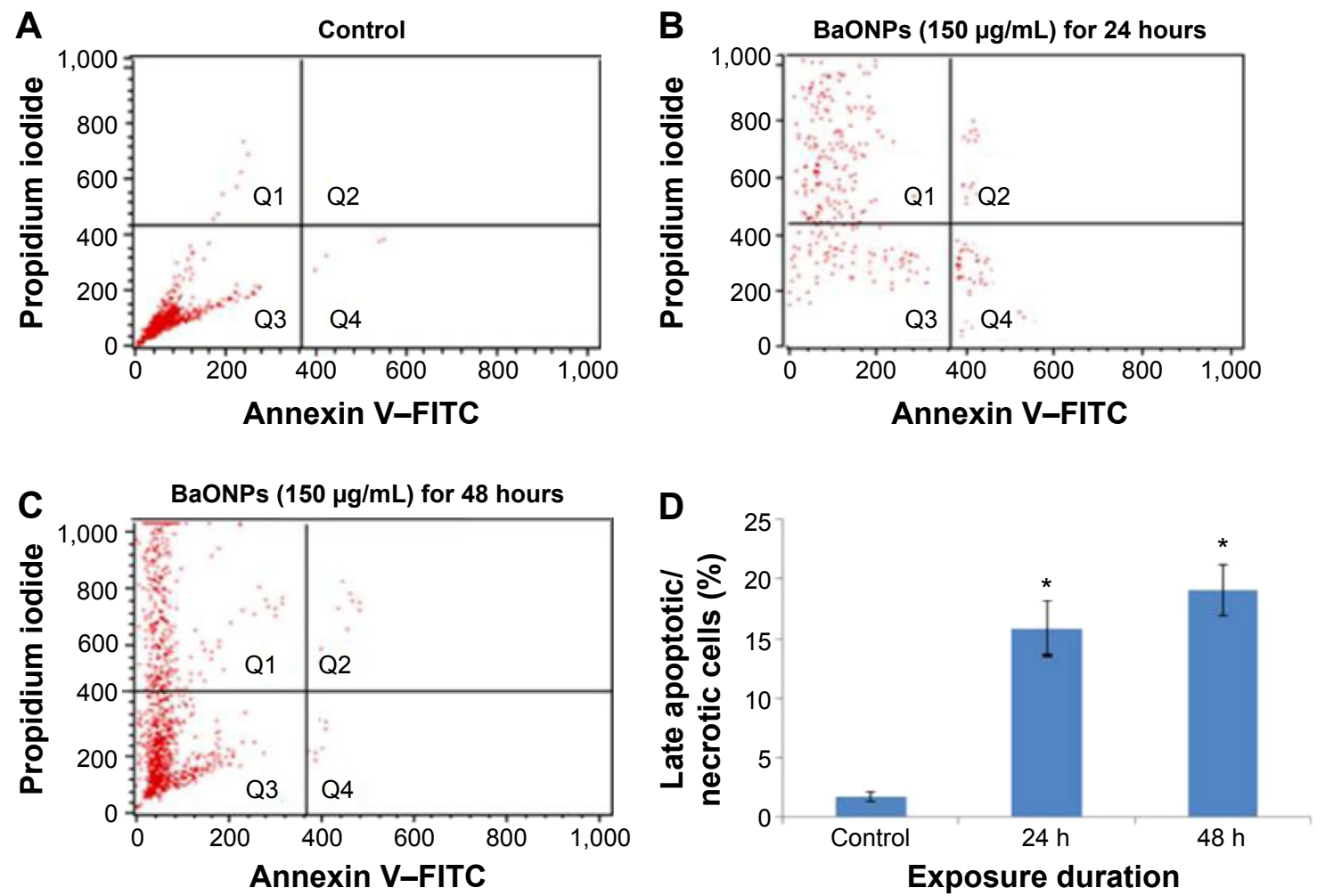

Figure 6 (A-C) Flow cytometirc analysis of Annexin V-FITC/PI stained cells. (D) Percentage of Annexin V-FITC/PI-positive cells in control and L929 cells exposed to BaONPs ( $150 \mu \mathrm{g} / \mathrm{mL})$ for 24 and 48 hours.

Notes: Each value represents the average \pm SE of two experiments. Statistical differences with respect to the controls are shown $(* P<0.05)$.

Abbreviations: BaONPs, barium oxide nanoparticles; FITC, fluorescein isothiocyanate; PI, propidium iodide; SE, standard error. 

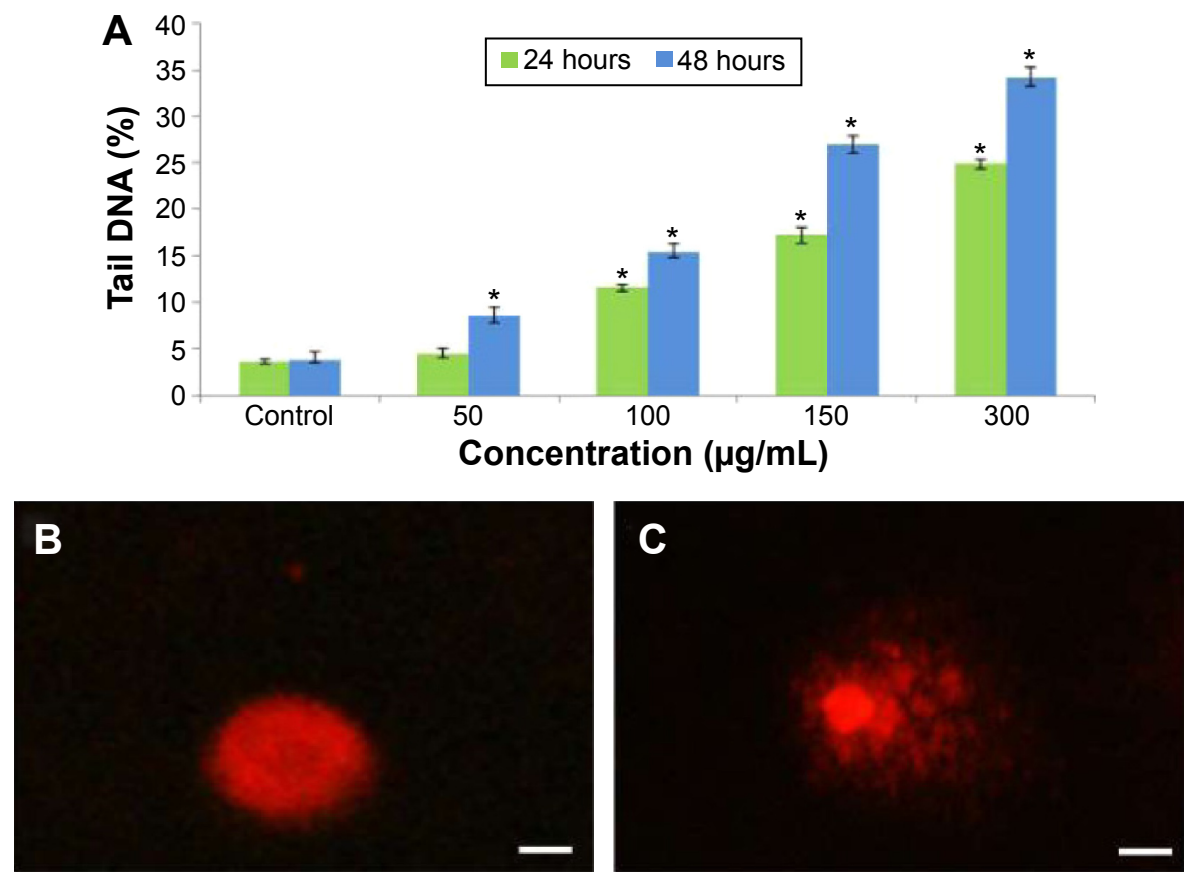

Figure 7 DNA strand breakage in L929 cells due to BaONPs.

Notes: (A) Tail DNA (\%). (B) Control cell. (C) Treated with BaONPs (I50 $\mu \mathrm{g} / \mathrm{mL})$ for 48 hours. Data represent the average \pm SE of three tests. Statistical differences with respect to the controls are shown $(* P<0.05)$. Scale bar $100 \mu \mathrm{m}$.

Abbreviations: BaONPs, barium oxide nanoparticles; SE, standard error.

cell death or carcinogenesis, consequently disrupting normal cell functions.

We found that DNA damaging effects of BaONPs in L929 cells by using comet assay, which is a technique used to identify double- and single-strand breaks and alkali labile sites even at low levels of DNA damage. ${ }^{25}$ Martinez et $\mathrm{al}^{26}$ reported that ROS reacts with DNA molecules, inducing damage to both bases (pyrimidine and purine) and the DNA backbone. This seems to be the underlying mechanism of BaONPsmediated cell toxicity and DNA damage in L929 cells.

\section{Acknowledgment}

The authors extend their sincere appreciation to the Deanship of Scientific Research at King Saud University for funding this research through the research Group Project Number RGP-180.

\section{Disclosure}

The authors report no conflicts of interest in this work.

\section{References}

1. Gillani R, Ercan R, Qiao A, Webster TJ. Nano functionalized zirconia and barium sulfate particles as bone cement additives. Int J Nanomed. 2010;5:1-11.

2. Hwang HM, Ray PC, Yu H, He X. Toxicology of designer/engineered metallic nanoparticles. In: Luque R, Varma R, editors. Sustainable Preparation of Metal Nanoparticles: Methods and Applications. Cambridge, United Kingdom: Royal Society of Chemistry; 2012:190-212.
3. Hiraoka M, Ikeda K, Sano T. The mechanism of barium-induced automaticity in ventricular muscle fibers. In: Tajuddin M, Das PK, Tariq M, Dhalla NS, editors. Advances in Myocardiology. Baltimore, MD: University Park Press. 1980;1:255-266.

4. Nayler WG, Grinwald PM. Dissociation of $\mathrm{Ca}^{2+}$ accumulation from protein release in calcium paradox: effect of barium. Am J Physiol. 1982;242(2):H203-H210.

5. Ostrovsky S, Kazimirsky G, Gedanken A, Brodie C. Selective cytotoxic effect of ZnO nanoparticles on glioma cells. Nano Res. 2009;2:882-890.

6. Mossman T. Rapid colorimetric assay for cellular growth and survival: application to proliferation and cytotoxicity assays. J Immunol Meth. 1983;65:55-63.

7. Wroblewski F, La Due JS. Lactate dehydrogenase activity in blood. Proc Soc Exp Biol Med. 1955;90:210-213.

8. Wang H, Joseph JA. Quantifying cellular oxidative stress by dichlorofluorescein assay using micro-plate reader. Free Radic Biol Med. 1999;27:612-616.

9. Bradford MM. A rapid and sensitive method for the quantitation of microgram quantities of protein utilizing the principle of protein-dye binding. Anal Biochem. 1976;72:248-254.

10. Ohkawa H, Ohishi N, Yagi K. Assay for lipid peroxides in animal tissues by thiobarbituric acid reaction. Anal Biochem. 1979;95:351-358.

11. Alarifi S, Ali D, Verma A, Alakhtani S, Ali BA. Cytotoxicity and genotoxicity of copper oxide nanoparticles in human skin keratinocytes cells. Int J Toxicol. 2013;32(4):296-307.

12. Ellman G. Tissue sulfhydryl groups. Arch Biochem Biophys. 1959;82: $70-77$.

13. Alarifi S, Ali D. Mechanisms of multi-walled carbon nanotubes-induced oxidative stress and genotoxicity in mouse fibroblast cells. Int J Toxicol. 2015;34(3):258-265.

14. Ali D, Ray RS, Hans RK. UVA-induced cyototoxicity and DNA damaging potential of Benz (e) acephenanthrylene in human skin cell line. Toxicol Lett. 2010;199(2):193-200.

15. Murdock RC, Braydich-Stolle L, Schrand AM, Schlager JJ, Hussain SM. Characterization of nanomaterial dispersion in solution prior to in vitro exposure using dynamic light scattering technique. Toxicol Sci. 2008; 101:239-253. 
16. Nel A, Xia T, Madler L, Li N. Toxic potential of materials at the nano level. Science. 2006;311(5761):622-627.

17. Asharani PV, Hande MP, Valiyaveettil S. Anti-proliferative activity of silver nanoparticles. BMC Cell Biol. 2009;10:65.

18. Konduru N, Keller J, Ma-Hock L, et al. Biokinetics and effects of barium sulfate nanoparticles. Part Fibre Toxicol. 2014;11:55.

19. Oberdorster G, Oberdorster E, Oberdorster J. Nanotoxicology: an emerging discipline evolving from studies of ultrafine particles. Environ Health Perspect. 2005;113:823-839.

20. Meister A, Tate SS. Glutathione and related gamma-glutamyl compounds: biosynthesis and utilization. Annu Rev Biochem. 1976;45: 559-604.

21. Kang SJ, Kim BM, Lee YJ, Chung H. Barium dioxide nanoparticles trigger p53-mediated damage response in peripheral blood lymphocytes. Environ Mol Mutagen. 2008;49:399-405.
22. Kroemer G, Petit P, Zamzami N, Vayssiere JL, Mignotte B. The biochemistry of programmed cell death. FASEB J. 1995;9:1277-1287.

23. Chen M, Mikecz A. Formation of nucleoplasmic protein aggregates impairs nuclear function in response to $\mathrm{SiO}_{2}$ nanoparticles. Exp Cell Res. 2005;305(1):51-62.

24. Alomar S. Cadmium sulfide nanoparticle induces oxidative stress and pro-inflammatory effects in human lung adenocarcinoma epithelial cells. Toxicol Environ Chem. 2015;97(5):619-633.

25. Collins AR. The comet assay for DNA damage and repair: principles, applications, and limitations. Mol Biotechnol. 2004;26(3):249-261.

26. Martinez GR, Loureiro AP, Marques SA, et al. Oxidative and alkylating damage in DNA. Mutat Res. 2003;544(2-3):115-127.
International Journal of Nanomedicine

\section{Publish your work in this journal}

The International Journal of Nanomedicine is an international, peerreviewed journal focusing on the application of nanotechnology in diagnostics, therapeutics, and drug delivery systems throughout the biomedical field. This journal is indexed on PubMed Central, MedLine, CAS, SciSearch ${ }^{\circledR}$, Current Contents ${ }^{\circledR} /$ Clinical Medicine,

\section{Dovepress}

Journal Citation Reports/Science Edition, EMBase, Scopus and the Elsevier Bibliographic databases. The manuscript management system is completely online and includes a very quick and fair peer-review system, which is all easy to use. Visit http://www.dovepress.com/ testimonials.php to read real quotes from published authors.

Submit your manuscript here: http://www.dovepress.com/international-journal-of-nanomedicine-journal 